\title{
Cicero Becomes an E-Book
}

\section{James J. O’Donnell*}

Cicero, it may now seem hard to believe, was not always an e-book.

Once upon a time, in fact, Cicero could be rather hard to come by. In the west Texas of my youth, excepting textbooks in the few schools teaching Latin, books by Cicero might have been found in a large public library, if there were such a thing, but even the present evidence that this might have been the case is not encouraging. The El Paso Public Library online catalogue reports one book in its print collection that can be said to be by Cicero, an advanced Latin textbook containing parts of one of his less famous works.

When he was to be found, he was found in hard covers. Printed from the earliest days of incunabula, he was often edited in Latin, and then increasingly often made available in translation in the nineteenth and twentieth centuries, though Latin editions preponderate in his history. The Princeton University Library online catalogue today contains approximately six hundred printed volumes or sets of volumes from before 1900 that consist mainly of works by Cicero. Many are of no interest whatever to scholars today, but some are almost exactly as useful as they were when written. (For example, I own reprint editions of at least a half-dozen such, and have handled and consulted many more).

The history of such editions and the description of the reading and scholarly practices that they embodied are topics for another place. Suffice here to say that these books fell into two broad categories: those for the use of students still acquiring a knowledge of the Latin language and Roman culture and those for the use of advanced readers, whether historians and scholars of the period itself or readers whose main interests lay elsewhere but who needed to read

* James J. O’Donnell is University Professor at Georgetown University, where he served as provost from 2002 to 2012 after many years on the faculty of the University of Pennsylvania. He is the author of Augustine: A New Biography (2005), The Ruin of the Roman Empire (2008), and Avatars of the Word: From Papyrus to Cyberspace (1998); his Passing of the Gods will appear in 2014. He is chair of the board of the American Council of Learned Societies (ACLS). 
and appreciate Cicero's works for their own purposes. A student of parliamentary rhetoric might be one such reader, but I became one when I was studying closely the Confessions of Augustine and looking to explore the dependency of the Christian saint on the Roman orator who died almost four hundred years before Augustine was born. (I delivered a paper, derived from those studies a quarter century ago, at a learned congress in September 20I2. The topic remains interesting and relevant, and consultation of the original works essential to its exploration.)

Readers of these books were slow patient readers. The rising students were slow by necessity, for Latin is a difficult language and Cicero a subtle and challenging author. (Our study of ancient languages is complicated by the near necessity of propelling students from the elements of grammar into the equivalents of Eliot and Faulkner in their intermediate courses.) The advanced readers were patient and careful for many reasons. In the absence of readily accessible digests, translations, and the like, one reading had to last its reader for a long time - hence careful reading and note-taking. So too the questions asked of an ancient text like this were often ones requiring minute attention to the nuances of language, with recourse to other texts, such as dictionaries. Though the proficiency of some such readers was remarkable, their habits made them patient. (Remarkable proficiency: Ronald Knox, said by some to be the brightest boy who had ever gone to Eton College, completed his Oxford classics degree in I9IO. At loose ends one summer morning that year, he decided to reread Plato's Republic, and so read the whole thing, that day, in Greek. The colleagues to whom I have told this story generally take a deep breath and allow as to how they might be able to do such a thing now, in scholarly middle age, with a fierce concentration of effort, but are clearly terrified at the thought of a twenty-two-year-old passing off such a task as a diversion for a summer's day.)

That was then. Very few readers of Latin today begin Latin as early as was once the case or pursue it so single-mindedly. George Orwell thought that a classical education was impossible without the employment of corporal punishment and the disappearance of both corporal punishment and formal Latin requirements have taken their toll. Those who learn the languages now start late, are much distracted by other concerns, and accordingly few advance to the highest levels. (Those who do, advance very far indeed, even in some surprising places. Quantifying differences in proficiency is difficult across the generations. When I read in an old Saturday Evening Post 
article of a celebrated federal judge circa 1950 who diverted himself from a difficult case in the evenings by consulting the poems of Horace, "of whose works he is a scholar," I may think nostalgically of such former times until I look at the deft and elegant translations from the Latin of "A.M. Juster," whose anagrammatic pseudonym thinly veils a very senior contemporary official of the United States government with no advanced degree in the subject. Things change in many ways, but not always clearly for the more or the less or for better or worse.)

In the last half century, the main development in the printed history of Cicero, as for many other authors and genres, came in increased availability. The paperback book made one advance, but the development of cheaper printing technologies and the expansion of markets with the now-fading big-box bookstores gave many more books a longer and wider life in print. In the 1970s, classical scholars were busy founding their own small garage-based publishing enterprises out of fears that the commercial market would fail them utterly; by the I990s, there was a robust market with numerous competitors providing textbooks and more, and the garage shops closed down. In that context, the appearance of Amazon.com represented not the first stage of the new age but the culmination of the old. When it was still hard to "special order" titles of books supposedly in print, Amazon made the decisive intervention in favour of swift, easy access to a huge list - what we now call the "long tail" of available books. Jeff Bezos's founding insight was that the economy of print books could stand one more revolution, and he has brought it about.

But in the meantime, electrons happened. In the prehistoric age of the e-book (I mean the I950s to the 1980s), scattered and brave initiatives arose. I leave aside the attempted mass-market appeal of Project Gutenberg, ${ }^{\text {I }}$ which undoubtedly gave visibility to an idea, an idea that it implemented very imperfectly. For classical scholars, the digitization of Greek literature took off rapidly in the I970s thanks to the work of the late Ted Brunner at the University of California, Irvine, who began keypunching Greek texts for the project known as Thesaurus Linguae Graecae (TLG), ${ }^{2}$ which had a

I Free Ebooks - Project Gutenberg, last modified 3 June 20I3, http://www. gutenberg.org/.

2 Thesaurus Linguae Graecae: A Digital Library of Greek Literature, last modified 28 May 2013, http://www.tlg.uci.edu. 
near complete database of ancient texts ready when the technology of displaying Greek fonts was revolutionized by the appearance of the first Macintosh computers in 1984. Even the most traditional and hidebound of classicists knew instantly, when they saw TLG demonstrated on a Macintosh at a learned meeting, that they needed that capacity immediately.

Latin followed more slowly. A small number of pioneers, notably Stephen V.F. Waite of Dartmouth College and David Packard of the Packard Humanities Institute, created e-texts of Latin authors. Waite organized a repository of "machine-readable texts" for the American Philological Association, while Packard ranged more widely. First, he produced a gigantic concordance to the works of Livy based on an electronic text he had keypunched and then sorted, printing it in a tiny typeface in four mighty volumes (now all either disappeared or long disused in our libraries). Later, drawing on the technology of the Hewlett-Packard Corporation with which he had family ties, Packard sponsored the creation of dedicated mini- and then microcomputers (called "Ibycus," after an ancient Greek poet), and then the creation of a CD-ROM containing the bulk of classical Latin literature. ${ }^{3}$ Gregory Crane, then of Harvard, now of Tufts University, was at the same time in the 1980s and 1990s developing the Perseus project, aggregating Greek and Latin texts, images, and reference works from a variety of sources. ${ }^{4}$ The net result of all this work was that by the time the networked personal computer had become ubiquitous in American society (call that the year 2000), an abundance of material was available.

Yet would we call this material "e-books"? Digitized texts, accessible through a computer screen, with whatever helpful features (e.g., the grammatical and lexical help built into Perseus) still felt alien for those brought up in the old ways. They had their uses, but it is hard to believe that anyone ever read a classical author from beginning to end on such a screen; and if there were exceptions, they were exceptions only. The new age had not begun.

Three factors have now changed the landscape. First, massive quantities of printed books have been digitized and made into something resembling a traditional book. Portable Document Format (PDF) files of printed books have many limitations, but one

3 The texts are now available at the Packard Humanities Institute, http://latin. packhum.org.

4 Perseus Digital Library, last modified 8 May 20I3, http://www.perseus.tufts.edu. 
curious strength is that they recreate at least some of the illusion of boundedness, control, and quality that came with the printed book. At least some of the reputation and prestige of the old publisher and editor (and copy editor and proofreader) come through the screen. Second, commercial publishers, driven to offer innovative reading interfaces, have turned to producing new works as e-books. No one is yet making serious money from Cicero, but the money that is being made in creating the environment is paying for a setting in which even Cicero can flourish. Third, many forces have converged on the creation of a new generation of hand-held devices, from smartphones to Kindle and Nook "e-readers" to iPad and Samsung tablets. These have the effect of creating another semblance of familiarity, by allowing a reader to use them for reading continuous texts in familiar places - beds, sofas, hammocks, coach seats on airplanes, etc. Longer battery life is undoubtedly a factor, but the portability and (in multiple senses) handiness are much stronger ones. I read a lot of Lolita on a laptop once, but it was and felt like a fluke. I managed to read most of David Copperfield on a tiny Blackberry a couple of years ago, breaking off not because of the technology but because I finally remembered how tedious I find Dickens. But in the last year I have also read all of Xenophon's Anabasis in Greek on an iPad (and the Count of Monte-Cristo and David Halberstam's Coldest Winter, besides). My iPad is now heavy laden with texts I actually read and, moreover, consult. E-reading is now possible and, it must be assumed, will be more and more prevalent as a practice even for improbably difficult and remote texts.

Here it is worth emphasizing the utility for the classicist of Google's mass digitization project. That project had many limitations. It seems now to have lost the interest of its creators and so progress in making the texts more useful has stalled - one sign of which is that the iPad app that one now uses to read them is called Google Play, ${ }^{5}$ for there are more people looking for games than for Cicero on their tablets. The Google project, however, had one great benefit: it digitized many texts. There is no classical author, I think it fair to say, that cannot now be found in a decently readable, if outdated and sometimes misleading, edition somewhere in Google Books ${ }^{6}$ or on the site of its envious cousin, the Internet Archive. ${ }^{7}$ My Kindle

Accessed I2 May 20I3, https://play.google.com/store?hl=en.

Accessed I2 May 20I3, http://books.google.ca/.

7 Accessed I2 May 20I3, http://archive.org/index.php. 
app is moderately full of books I have paid for; my iBooks app has a variety of odd things in it; and my Google Play is chock full of ancient works in editions ranging from passable to pretty good, and I use them regularly. (That the iPad also allows easy network access from one's hammock makes other sites, such as Perseus but also Wikipedia, far more useful than they had been, and I find myself consulting them much more frequently than ever before.)

So Cicero is now an e-book - or rather, many e-books, in many formats. We will wrestle for years to come with the underlying notion of "book" - what it takes to make a string of words into that kind of ambitious, self-contained, and extensive but bounded space of the imagination. (Whether it contains "fact" or "fiction," it is imagined). The boom in e-books in the last five years has proven that we were waiting for something, whether an end state or a transition, to make us comfortable with translating the "book" experience into the world of pixels and screens.

I take it as given that the transition has now happened. It will take many years for the implications of the transition to play out. I suppose I must be prepared for the idea that some form of Google glasses will be bringing me Cicero in five years as I walk down the street, hands in pockets, Cicero's words projected before my eyes on a blue-sky background, me hoping not to be so distracted by him that I get run over by a bus. Some such future is a given: devices will evolve and become more convenient, in ways that by definition we do not now anticipate. Only one question remains open, and I will return to that.

For now, we have gained and lost. What have we gained? Accessibility, ubiquity, propinquity, ease - immeasurably. If I have network access, the merest flicker of a desire to glance at a minor work of Cicero can be blown into flame and then extinguished in a matter of minutes if not indeed seconds. I am no longer behind on my New Yorkers because the magazine format so suits the odd bits of time in waiting rooms, queues, and fast food joints. I can read Greek and Latin anywhere, with the basic tools at hand, not needing any longer to get home to my desk, dictionary, and unique printed text. Forty-two years ago, in order to have a copy of Lucan's poem on Rome's civil war all my own, I had to write away to a Blackwell's bookshop in Oxford and wait six weeks for it to arrive. I just tested myself with laptop and iPad: it took about sixty seconds from a standing start to reading the first page of the text on my "own copy" of an eighteenth-century edition. 
There, however, is the great loss. That eighteenth-century edition of Lucan was a worthy effort in its time, but it is a mess by modern standards, inaccurate and misleading in hundreds of ways. A.E. Housman's edition of 1926 cleaned up the punctuation in particular and made sense out of many passages (including that first page) that had baffled or misled readers for a long time. It matters to me and should matter to many that I be able to use the best possible edition in the best possible way. In the world of modern publishing, two things get in my way. First, the terrible mess created by the train wreck that occurred when accessibility and e-availability ran into copyright law. The best editions of a great many classical authors are not available in electronic form; of those that are, most are sold by large publishers at substantial prices in a variety of conflicting formats that often do not let me use the book anywhere near as well as I could have used it in paper form. The revolution of access is a crisis of access, not made better by the zealots who insist that everything be available for free. Not only do those insistences not solve the problem of how we pay for the real - even if reduced - costs of publication, but they also have had the effect of deterring movement toward better ways of getting at texts.

The second loss is exemplified by ridiculousness: the book that I bought the other day from the iTunes store for my iBooks app has footnotes that simply do not link. The notes are there in the "back" of the book, but I get no help whatever in navigating from the footnote call on the page to the correct note page in the back. The average time to consult a "footnote" is ninety seconds, even when the note turns out to be not worth reading. Publisher and app designer alike should be embarrassed to sell such books.

Some of these presentation and format issues about which I complain will go away or get better with time, no question. A program that can display linked notes is not a technologically sophisticated thing to create, but it is socially complex: not only do we need a format, but we need a standard format, so that I may move from one book to another as easily as I did with paper volumes thirty years ago. Take that as a representative case: all of the seemingly technical problems we face with e-books are really social problems. Obtuseness impedes progress. Sometimes this is the obtuseness of laws not written to address our technologies and their opportunities; sometimes it is just obtuseness.

It is also unforgivable that Apple, Amazon, and Google, all of them together, have not yet figured out how to apply appropriate metadata 
to the books they purvey. The genius of librarianship lay, among other places, in the Machine-Readable Cataloguing (MARC) record and similar standard formats for providing accurate information about the contents of the things that were in libraries. To prove the difficulty, I ask my students to look at Google Books and see if they can acquire a complete set of the three volumes of J.E. Sandys's History of Classical Scholarship, published in the first years of the twentieth century. The surprise they encounter is not merely that they cannot (volumes 2 and 3 are available), but that it takes a fair amount of work to find out whether they can. Amazon is scarcely less messy, partly because the world of shopping for print books like this is now flooded with the offer of print-on-demand copies, derived from Google and Internet Archive representations, and the quick-money entrepreneurs who produce such things have even less respect, if that were possible, for metadata than do the giant corporations. (The only thing that helps me when I go to Amazon for Sandys is the fact that an old-fashioned publisher, Cambridge University Press, has lately added Sandys to their line of print-on-demand volumes, and that they have taken some care with the metadata. Amazon print books and e-books are typically poorly represented as well.)

Do the annoyances of instant access significantly contravene the benefits? The answer to that question depends entirely on the use to which I am putting the material. If I am reading a novel on the train or if I am reading Lucan merely for pleasure at the beach (it happens), no. If I am a serious reader, standing in the long tradition of western cultures that take books and their contents seriously, then often the answer is yes. There is a splendid new book, for example, called The Jewish Annotated New Testament (Oxford, 20II), edited by two distinguished scholars with a long list of scholarly contributors offering the early Christian writings surrounded by annotation and discussion of the Jewish contexts from which they arose. I will read this book when it emerges in paperback, because the hardcover is too bulky for my iPad-attuned hands and my purpose, but also because the Kindle book has been misdone in its own clumsy way, with no attention to page layout (and thus loss of clarity) and by converting the notes to links. In the printed book, the notes appear on the page; in the Kindle, one must click on each one to read it and then press the right button to go back to the text. No, thank you: too slow. This e-book has positively obstructed my desire to read that work - and I am speaking only as the unscholarly reader. When I really need my Cicero for my best scholarly purposes, I know I am still some years 
at least away from being able to take full advantage of him. Cicero is an e-book - but he has a good way to go in order to become as useful as he has been in his p-books.

Then there is the question to which I promised to come back. Many times in the last thirty years I have thought of Marshall McLuhan's old principle that the content of a new medium is an old medium - at first. Motion pictures began by setting up a camera in front of something like a play; printed books transcribed and even imitated the format of manuscript books, and so forth. The story I have told is of the emergence, more gradual than we expected, of an electronic artifact that merits the name of "book." We know it is a book, as I have said, because we find in it the qualities we have come to associate with books: extensive but bounded, strong "production values" (editing, proofreading, presentation), intellectually ambitious on some axis or other, and presented to us at the end of a process of selection and validation. When you show me an e-book that has those qualities, I know how to recognize it, appreciate it, and use it, with whatever frustrations.

But can we - can I - come to a point where I forget printed books? Or, if not forget, then learn to treat them the way I treat my fountain pen, namely, as something splendid, useful within limits, seen by others as an affectation, and mostly neglected because other ways of accomplishing the same task (such as the laptop on which I now type) loom larger in my life?

The idea of compressing thought and experience into a finite number of "pages," however measured, is very old. The Iliad and the Odyssey for length resemble the latest Martin Amis novel, Plato's Republic is not unlike John Rawls's Theory of Justice, and the notes in the margins of medieval manuscripts of classical and biblical authors share form and often content with modern scholarly commentaries. They assume an intensity of composition and then an intensity of reading that have proven remarkably stable over time. What we do not know, and will not know until we suddenly know it, is whether the underlying culture of the chosen and frozen word will persist that culture of saying the thing well and carefully so that it can be carefully and well read.

The challenge is a matter of attention. How much is there to read, to hear, to see, and how much time do we have? The Clerk of Oxenford in Chaucer's Canterbury Tales owned twenty-five books - a substantial library. I have had nearly that many piled on my nightstand, all claiming that I will read them someday real soon now, 
a claim most often made in vain. Cicero (p-book Cicero and e-book Cicero) will scarcely disappear, but he already looms smaller in our culture than he once did. (He has been on my nightstand.) How small can he become? And what becomes of us as he dwindles? The emergence of the e-book after decades of expectation heralds, I predict, the emergence of those questions with new force and meaning.

\section{SOMMAIRE}

Cicero n'a pas toujours été numérisé, mais il l'est aujourd'hui et en de nombreux autres supports. Nous sommes en butte actuellement avec la notion sous-jacente de livre, ce qui en somme fait qu'une suite de mots deviennent cette sorte d'espace imaginaire et unique, animé d'ambition et se déployant à grande échelle. L'augmentation des livres électroniques durant les cinq dernières années a démontré que nous sommes en attente de quelque chose, soit en phase finale ou transitoire, afin de nous conforter à l'idée que le devenir du livre puisse se convertir en pixels sur des écrans. Qu'ont gagné les lecteurs et les chercheurs en consultant des livres numériques? qu'ont-ils perdu en retour? Cicero est maintenant sur support électronique, mais il est en bonne voie de s'avérer aussi utile qu'il était jadis lorsqu'il se présentait en version papier. 